\title{
O PAPEL DO CONSELHO ESCOLAR DE MOÇAMBIQUE NO DESEMPENHO DAS ESCOLAS PRIMÁRIAS
}

\section{ARTIGO ORIGINAL}

MEIA, Aleque Joaquim ${ }^{1}$

BECHANE, José ${ }^{2}$

MEIA, Aleque Joaquim. BECHANE, José. O Papel do Conselho Escolar de Moçambique no desempenho das Escolas Primárias. Revista Científica Multidisciplinar Núcleo do Conhecimento. Ano 05, Ed. 10, Vol. 12, pp. 168-181. Outubro de 2020. ISSN: 2448-0959, Link de acesso: https://www.nucleodoconhecimento.com.br/educacao/conselho-escolar

\section{RESUMO}

Este artigo procura congregar uma abordagem acerca dos fundamentos teóricos e práticos do desempenho, seu impacto, implicação na escola e sociedade. Traz uma reflexão sobre o papel do Conselho Escolar no ensino primário em Moçambique, tendo como caso de estudo a Escola Primária Completa de Canongola, do distrito de Tete e Província do mesmo nome. Este trabalho, ao longo da sua abordagem basearse-á nos procedimentos metodológicos da pesquisa qualitativa e subsidiado pelo tratamento estatístico na análise dos dados em relação aos questionários e entrevistas. As entrevistas foram aplicadas aos componentes do órgão do conselho escolar, tais como, diretor da escola; diretores Adjuntos pedagógicos; chefe da

${ }^{1}$ Mestrado em Educação-Formação de Professores, pela Universidade Europeia de Atlântica, Instrutor e Técnico Pedagógico do nível superior e Licenciado em Psicologia.

${ }^{2}$ Mestrado em Educação-Formação de Professores, pela Universidade Europeia de Atlântica, Instrutor e Técnico Pedagógico do nível superior e Licenciado em Português. 
Secretaria; oito professores; quatro alunos; uma presidente do conselho; um secretário do conselho escolar e quatro pais de turmas. Foram estes que preencheram e responderam os formulários correspondentes aos membros ou representante de cada órgão. $O$ estudo revela que há um enorme desafio no procedimento da gestão nos planos das escolas primárias por razões de várias ordens. A reunião do Conselho da Escola Primária Mateus Sansão Muthemba, cuja agenda era a eleição do presidente e secretário do Conselho Escolar. O estudo identificou a violação de algumas normas que regem o manual da constituição do Conselho Escolar, pois além do diretor, que é o único membro isento da eleição, existem outros indicados e não eleitos no conselho da escola. O estudo mostrou nos, também que, apesar da participação dos membros da comunidade nas reuniões do Conselho Escolar, na prática, eles têm pouco protagonismo no decurso dos encontros, o que mostra ainda forte influência do segmento dos professores, isto é, o gestor da instituição no tipo de decisões tomadas pelo Conselho Escolar.

Palavras-chave: Educação, Escola, Conselho Escolar.

\section{INTRODUÇÃO}

O presente artigo, tem como resultado de reflexões do trabalho que tem vindo a ser desenvolvido pelos conselhos escolares do nosso Pais, Moçambique existe o envolvimento dos país e encarregados de educação, onde fazem se representado pelo órgão denominado Conselho nas escolas, e esta prática tem-se verificado desde o período pós-independência quando as primeiras experiências dos pais e/ou encarregados de educação, começam a se fazer sentir através das comissões de pais e de Ligação Escola Comunidade designando por LEC. Esta Lei no 6/92, de 6 de Maio, reforça de algum modo o envolvimento, que orienta a participação efetiva de outras entidades competentes, incluindo as comunidades no seu desempenho nos processos educativos e incentivando uma maior ligação entre a comunidade e as instituições de ensino.

Os conselhos escolares nos nossos estabelecimento, principalmente ao nível de ensino primário, tanto quanto aos outros níveis, é evidente que existem pela 
necessidade muito relevante na disponibilidade em que há abertura da escola nas comunidades locais através do apoio da legislação que é regulamentado pelo Diploma Ministerial através do oㅜ 54/2003, datado a 28 de Maio, pela mesma força da lei no contexto da descentralização administrativa do território nacional, que visa procurando criar maior dinamismo em todos os processo de planificação e tomada de quaisquer decisões através duma participativa conjunta com deste órgão em destaque.

O estudo apresentado neste artigo, é consequência duma investigação e observação no dia-a-dia no processo da avaliação da participação dos pais e encarregados de educação em volta de muitas escolas, como a necessidade de lançar um olhar na perspectiva de trazer e inspirar uma capacidade na gestão de novas abordagens de forma coerente em função da real situação e mediante a cada realidade que acontece em cada escola primária e em particular destaque na Escola Primária Completa de Canongola, onde o conselho escolar não revela nas suas competências em relação à direção da escola. A pretensão era realmente compreender como é que os atores visados no processo, Conselho Escolar da escola primária se envolvem ou se empenham quanto a sua participação no processo de tomada de decisão na aprovação dos planos de ação.

\section{METODOLOGIA}

Conforme Marconi e Lakatos (2007), tem o entendimento que permite perceber que, método é o conjunto das várias atividades sistemáticas e racionais que, com maior segurança e ou domínio, com vista ou que leva nos a alcançar os objetivos, conhecimentos relevantes traçando o meio a ser seguido, detectando erros e auxiliando as decisões do cientista. Estas abordagens ou métodos ajudam a estabelecer critérios na classificação do trabalho de qualquer natureza de pesquisa. E neste caso em referência, esta reflexão insere se na pesquisa exploratória que tem como fim de proporcionar grande assimilação com o problema de forma a torná-lo mais claro no arrolamento de várias hipóteses para qualquer objeto de estudo.

Neste sentido, levou nos a querer fazer a verificação se há necessidade de aplicar a funcionalidade da pesquisa exploratória na perspectiva de que permite nos trazer 
maior envolvimento de levantamento bibliográfico; entrevistas de pessoas de experiência e práticas, e análise que estimula a compreensão (SELLTIZ et al, 1967), na finalidade de fornecer a sociedade provas do fundo e de maior clareza da razão principal que põe em causa o órgão do conselho escolar no desempenho nas escolas primárias, no caso concreto na Escola Primária Completa Canongola. De tal maneira que o Lakatos fundamenta o processo em relação aos métodos a serem caminhos que permite chegar num determinado ponto, e este fenómeno leva-me a percorrer diferentes formas, para assim, atingir alguma verdade básica no objeto de estudo deste artigo.

Tenho o entendimento que, para o efeito, poderiam ser usados vários métodos que permitiriam a alcançar os resultados, mas que urge a necessidade de conjugação de quantitativos para os dados mensuráveis e imensuráveis. Todavia, porque a pesquisa é predominantemente qualitativa, os dados foram analisados sob forma interpretativa através de categorização em padrões, que produziram sínteses narrativas descritivas.

Conforme o objetivo que nos comoveu a escrever ou laborar este artigo, é que a pesquisa tende a analisar ações do Conselho Escolar que podem ser desenvolvidas para melhorar o desempenho nas escolas primárias, tornando como modelo para várias instituições de ensino, que possam seguir como modelo de referência.

Ao nível dos três grupos inqueridos no campo de estudo, observamos que na realidade o Conselho Escolar após a análise, viu-se que um dos maiores obstáculos tem a ver com o tipo dos membros que se tornam representante da sua comunidade não reúnem capacidade de gestão das suas ações, tanto como consequência, não tem havido plano concreto de cumprimento do seu mandato.

Durante o trabalho de campo, tivemos algumas ocasiões de assistir reuniões programada do Conselho Escolar, constatamos que havia falta do fórum apropriado para o órgão se reunir e deliberar assuntos pertinentes.

Durante o estudo identificamos que na maioria dos entrevistados convergiram as suas sugestões em relação as normas que regem a constituição do Conselho Escolar, pois 
além do diretor que é o único membro isento da eleição, existe outros indicados e não eleito. Outro aspecto está relacionado com a representatividade na constituição do Conselho Escolar, pois o presidente do órgão tem sido na maioria das vezes o influente do membro da direção. Nestes aspectos, Werle (2003), como citado em Luiz e Conti (s/d), refere que o Conselho Escolar deve ser eleito por voto secreto e constituído por todos os segmentos da comunidade escolar.

Neste estudo observamos também que, apesar da participação dos membros da comunidade nas reuniões do Conselho Escolar, na prática, eles têm pouca contribuição em opiniões motivados pela falta de domínio do órgão que ostentam no decurso dos encontros, o que mostra ainda forte influência do segmento da direção da escola no tipo de decisões tomadas. Revelou ainda que a escola funciona segundo uma estrutura vertical, com o director no topo e os outros nos escalões inferiores, aliás, esta é a estrutura formal em vigor nas escolas públicas, conforme plasmado na Política Nacional de Educação (PNE).

$\mathrm{Na}$ participação deste órgão, Conselho Escolar, a legislação do nosso Pais, Moçambicana, associa se ao funcionamento pleno, centrando se na melhoria do desempenho das instituições de ensino, na medida em que os pais podem acompanhar regularmente o desempenho dos seus filhos (MEC, 2005). No caso concreto apesar de trabalhar em ambientes urbano o Conselho da Escola possui aspectos como vários outros que podem revelar alguns aspectos para o seu fracasso, tais como: ausência do presidente do Conselho Escolar em algumas ocasiões pertinente, como consequência, fica em causa a consolidação do papel; menos envolvimento dos pais e encarregados de educação no Conselho Escolar; exigência de remuneração dos membros do Conselho Escolar e falta de acções de capacitação dos membros do Conselho Escolar o que pode contribuir para o seu fraco rendimento no funcionamento do conselho da escola (MEDEIROS e OLIVEIRA, 2008).

A partir do presente artigo, temos a propor no geral algumas sugestões de qualificações e que podem ajudar o funcionamento chave que permite ao órgão do conselho escolar que esteja bem consolidado das competências no desempenho das 
suas funções, que servirá de modelo para vários órgão do Conselho da Escola no nosso ensino em Moçambique, assim sendo, orienta se nos seguintes aspectos:

- Adequação dos requisitos mínimos à candidatos a serem elegíveis ao órgão;

- Criação de formas de acompanhamento e assessoria do Conselho Escolar, como forma de assegurar o funcionamento efetivo;

- Criação de angariação de fundo de funcionamento do Conselho Escolar para garantir condições necessárias ou boas na participação dos pais e encarregado de educação;

- Geração de planos de ação e solicitação de prestação de contas nos seus respectivos segmentos;

- Instituição da obrigatoriedade na capacitação dos membros do Conselho Escolar por forma a qualificá-los a discutir os problemas reais da escola;

\section{REVISÃO DE LITERATURA}

\section{EDUCAÇÃO}

Ferreira (2009), levou-nos a crer que a educação é um processo que permite o desenvolvimento de capacidades físicas, intelectual e moral de criança e de ser humano em geral, visando à sua melhor integração individual e social. Nesse sentido, a educação sendo um processo de formação do homem, ocorre durante a convivência social, ensinando e aprendendo, não só na escola, mas sobretudo, na vida, dai que, o fundamento de que o papel da educação como processo e considera a escola como uma via importante para a realização ou execução de uma educação humana que considere a disciplina no agir, onde o individuo aprende na medida em que faz as escolhas que o modifica a si e aos outros.

E para Oliveira (2000) oferece a possibilidade de que o processo educativo que, o homem deve ser considerado no plano físico e intelectual consciente das possibilidades e limitações, capaz de compreender e refletir sobre a realidade do mundo que o cerca. No outro sentido, Kant quer distinguir o homem do animal é porque o homem tem esta capacidade de se formar e educar-se para servir a sua 
comunidade através da capacidade intelectual, cujo esta capacidade que o homem tem de se transformar contribuí bastante para a sua própria sociedade

Do conceito aprendido sobre a educação, depreende-se que os fins educacionais se relacionam com os papéis que os indivíduos desempenham dentro da sociedade. Neste contexto, a educação e a sua prática estão dependentes do tempo histórico e de fatores políticos, sociais, económicos e culturais. De igual modo que é apontando para a mesma direção, (REBOUL, 1971) considera a educação uma ação consciente que leva nos a permitir que sejamos um ser humano oriundo de capacidade em desenvolver as nossas habilidades físicas e intelectuais bem como os sentimentos sociais, estéticos e morais, com o objetivo de cumprir tanto quanto possível a sua missão como homem. Em conformidade com o resultado da educação, surgem várias ações.

\section{ESCOLA}

Na percepção de Guedes (2009), define o termo escola, como é lugar de ócio, espaço em que os homens livres se juntavam para pensarem e refletirem sobre suas vidas. $E$ temos afirmar que Aristóteles previa a escola ao ar livre, onde o mestre e discípulos pudessem divagar sobre os mais variados temas sem pretensão do prático e da pressa. Neste sentido, a arte da razão e do saber, previa algo prazeroso, ou seja, Sapororis (sabor e razão).

Nesta fundamentação teórica a que saber que deveria ser fenomenal que inspira aos homens no seu dia-a-dia no processo de ensino-aprendizagem. E atualmente o lugar concebido como espaço da escola, verifica se uma diferença do mesmo espaço, que trata se de condições avançadas. Para fazer fácil a comunicação entre as instituições, tem sido através do próprio sistemas de aprendizagem, onde as sociedades frequentam nas tais escolas, assim como no mundo moderno, atualmente a escola refere se ao estabelecimento público ou privado onde se ministra sistematicamente, o ensino coletivo (FERREIRA, 2009). 
Freire (2003), como citado em Dalbério (2008) os pais não devem ir a escola para receber repreensões, advertências, reclamações ou trabalho, mas sim para participarem com os seus saberes e experiências, para poder trazer bom rendimento na própria vida estudantil dos seus educando nestas instituições, razão pela qual, são convocados para o acompanhamento dos seus filhos em qualquer situação possa existir de forma que, estes compartilhem as decisões sobre a orientação da educação no processo de aprendizagem.

Embora vimos alguns conceitos a respeito da escola, Gramsci (2000) citado em Taborda, Petrenko e Monteiro (2009) consideram que a escola não é só o lugar, mas sim um instrumento utilizado para formar intelectuais de diversos níveis. Por intelectuais Gramsci refere-se a todas as pessoas que exercem funções de organização em diferentes frentes, nomeadamente: na produção, na cultura ou na administração pública. Nesta perspectiva, a Escola Primária Completa Canongola pode ser um instrumento para a formação dos quadros para servir melhor a sua comunidade.

Contudo, consideramos também a apreciação relevante de Gramsci em reconhecer que a escola somente pode oferecer o ponto inicial para o desenvolvimento de uma nova concepção do mundo, visando a formação de um novo intelectual. Tal intelectual está relacionado ao organizador que, além de elaborar e dar a organicidade as formas de pensar e compreender o mundo, seria o responsável por sua veiculação em todos aspectos da sua própria sociedade, dai que nasce a necessidade de haver um vínculo de parceria na escola em relação ao conselho escolar.

Na perspectiva ainda do Gramsci (2000) como citado em Taborda; Petrenko e Monteiro (2009), admite que a escola tanto pode atuar para a manutenção da ordem existente como para a transformação do homem pelo processo de aprendizagem nos nossos sistemas de ensino, dependendo da correlação entre a comunidade e a instituição de ensino, que dá suporte da manutenção que a escola pode fazer é em relação na transparência de gestão das instituições que culmine no melhor desempenho do conselho escolar na sua participação em representatividade da comunidade. É escola porque dele ser justificado por uma justa correspondência com 
todas as esferas da sociedade, assim como o órgão do conselho escolar ao nível das escolas no ensino primário em Moçambique.

Em todos os processos que visam o funcionamento, tem se caracterizado por algumas vezes interferências que tende a levar o fracasso na tomada de decisões à vários níveis de direções das escolas, não tem caracterizado a boa liderança, assim como pode se verificar em algumas escolas primárias em Moçambique. Tantos estes conceitos de diferentes autores é para trazer mais evidências nas abordagens de formas diversificadas de como as lideranças podem proceder uma interligação com o conselho escolar, em particular na Escola Primária Completa de Canongola.

\section{CONSELHO ESCOLAR}

Para entendermos um pouco do que está sendo tratado a respeito do órgão Conselho Escolar recorremos aos autores Ferreira e Aguiar (2004), para trazer o significado, que se refere a tanto ouvir alguém quanto submeter algo a uma deliberação de alguém, após uma ponderação refletida, prudente e de bom senso, está a virtude que é conceituado pelo autores que é principalmente que ocorre no modelo regulamentado nos órgão.

No grande Dicionário Enciclopédico Verbo (1997), define também o termo Conselho como um organismo que pode possuir diferentes funções, tais como funções consultivas, técnicas e executivas onde está instituído, e que é fundamentalmente este princípio que traz a funcionalidade nas nossas escolas primárias.

Conforme (REGEB, 2008), o Conselho da Escola é o órgão máximo do estabelecimento de ensino, e que tem como funções de regular os princípios fundamentais das instituições de ensino e as respectivas metas estabelecidas a vários níveis, tais como, central, orientações que estão instituídas no topo e local onde abrangem ao nível da base, que à qualquer a realidade da escola este órgão é estabelecido com o propósito de garantir o bom desempenho do mesmo na gestão democrática, solidária e co-responsável. 
A relevância desse artigo encontra em consonância com o princípio de Cruz (s/d), ao afirmar que o termo "conselho" embora seja amplamente utilizado para designar diferentes formas de organização ou outras reunião de várias natureza política, tanto no sector da educação assim como nos outros meios passou a considerar-se mais recentemente como um mecanismo de gestão do sistema de forma a garantir o bom desempenho nas escolas primária, porque a escola é de controlo popular de políticas públicas. Razão pela qual que, alguns pesquisadores afirmam que o termo conselho surge no sector da educação, como forma de institucionalizar a participação da comunidade representada pelo conselho escolar nos processos de bom desempenho escolar numa perspectiva democrática.

O conselho pode ser um órgão onde a razão se aproxima do bom senso comum. Para este estudo, conselho significa uma reunião ou assembleia, onde as pessoas se reúnem para deliberar sobre questões de vários âmbitos, tais como: pedagógico, financeiro e administrativo. Com este posicionamento que um conselho escolar é legitimado, caberá na estrema máxima o órgão de tutela elaborar plano de ação que visa a realização das suas tarefas sem sob influência da direção da escola.

No entender de Cury (2004), considera que o conselho é constituinte de um lugar onde se os membros do conselho reúnem para deliberaram decisões para o bom funcionamento daquela escola onde estiver inserida. Por isso, toda a decisão deve ser precedida de uma análise e discussão dos participantes. A ser assim, atendemos que há necessidade imperiosa dos membros do conselho da escola a serem constituídos no órgão, que fossem indivíduos ou pessoas que reúnem requisitos eficientes para estarem em altura de responder as exigências ou competências no desempenho das funções.

\section{DISCUSSÃO}

No nosso contexto, em cada direção da escola no Pais é recorrente a influência na tomada das decisões e orienta as discussões, culminando em aparente figurativo, o conselho escolar não tem tido o poder proativo, queira nas reuniões do conselho da escola, nem nas assembleias gerais da escola e consequentemente não traz impacto 
no processo do desempenho efetivo. Os dados obtidos mostram que o conselho escolar não tem poder efetivo nas escolas de Moçambique. Desta forma, o objetivo do presente estudo é de analisar ações do conselho escolar que podem ser desenvolvidas para melhorar o seu desempenho nas escolas primárias, concretamente no Conselho escolar, através do envolvimento na comunidade local, onde tomam as decisões e resolução dos problemas que afetam a vida da escola.

Nessa perspectiva, Luck (2006), afirma que o Conselho Escolar deve promover aos membros do conselho da escola na participação efetiva da comunidade nos processos de administração e gestão da escola, visando assim assegurar a qualidade do trabalho escolar em termos administrativos, financeiros e pedagógicos.

Entretanto, o papel que o conselho escolar desempenha nas instituições de ensino, sendo uma estrutura inovadora, que implica mudanças profundas no comportamento dos gestores de escolas, a sua implementação tem conhecido alguns constrangimentos (FONSECA1998: p89). Tais constrangimentos estão relacionados com a resistência a mudança, formas de participação passiva e críticas ao seu modelo constitucional.

Na perspectiva do autor, em algumas escolas, os órgãos de Conselhos Escolar são criados, porém, não desempenham o seu papel efetivamente, quando muito dos membros reúnem-se para apenas aprovar as deliberações ou projetos apresentados pela direção da escola, o que contraria o princípio da gestão participativa e transparente.

Neste contexto, é evidente perceber que este órgão, o conselho da escola, quase tem a sua representatividade menos consistente nos estabelecimentos de ensino primário, pelo facto do fraco desempenho do seu papel nas escolas. Pode se entender que, este órgão é constituído para desempenhar o seu papel pela qual foi instituído. Realidade que se constata nas escolas púbicas em Moçambique, e em particular na Escola Primária Completa de Canongola (EPCC), os membros são estrategicamente selecionados para a composição do órgão, que este passa a representar a sua comunidade na escola, mas que, sem um domínio a altura para discutir e trazer uma 
planificação das atividades a serem desenvolvidas durante os seus dois anos de mandato. Era de esperar que os membros eleitos que pudessem ter requisitos com uma visão de consentir as suas funções que thes são incumbidas. Mas não se observa com rigorosidade os critérios seguramente para permitir que algumas direções das escolas possam coagir aos membros em seus benefícios.

O pensamento da apresentação deste artigo é para trazer algumas perguntas que podem ajudar a perceber com clareza o engajamento do desempenho do conselho escolar. Conhecer na essência a razão do fraco desempenho deste órgão? Qual envolvimento correto no papel que poderia colocar este órgão na participação efetiva. Como órgão que esta em sintonia na administração das escolas. Será que os membros que formam o conselho escolar têm reunido requisitos adequados e correspondentes às funções para ajudar a sua escola, de modo a ter a precisão de implementar o plano (MINED, 2008).

Reconhecendo a competência de cada membro eleito, temos a propor algumas sugestões possíveis que podem ajudar a contornar ou melhorar o seu desempenho de cada membro do órgão nas escolas primárias em Moçambique. O estado moçambicano sempre deu primazia ao Ministério de Educação, na reformulação do guião que sempre procura oficializar a composição dos membros do conselho escolar, com maior interesse de interação no critério de seleção correspondente ao nível de ensino, podendo assim, restabelecer o equilíbrio do órgão em relação às direções das escolas quanto ao seu desempenho. Por outro lado, o conselho escolar sendo fornecido os relatórios de prestação de contas em cada período das atividades, pode ainda reconstituir se a sua posição como estrutura máxima na escola.

O estudo em causa tem em vista análise reflexiva da pesquisa feito na produção deste artigo; tendo mostrado se muito relevante na medida em que ajudar a minimizar os fracassos e maximizar a potencialidade do órgão instituído pelo governo por forma a combater da fragilidade no desempenho do conselho escolar nas instituições de ensino em Moçambique e em particular na Escola Primária Completa de Canongola e que permitiu a investigação e esclarecimento das razões que impedem o maior envolvimento nas tomadas de decisões. 
$\mathrm{Na}$ qualidade técnica de educação, percebe se que há uma responsabilidade de identificar e refletir sobre os problemas educacionais e, através dos estudos, propor algumas possíveis soluções ao problema levantado. Nesse sentido, a crescente insatisfação dos pais e ou encarregados de educação no trabalho desenvolvido pelos Conselhos Escolares nos últimos anos, criou em nós neste trabalho, a necessidade de efetuar esta reflexão para, de uma forma específica, contribuir com maior abertura, por forma a chamar mais contribuições sobre o tema e que irá congregar inúmeras propostas que visam melhorar o desempenho do conselho escolar no ensino primário das escolas, e em particular atenção a Escola Primária Completa Mateus Sansão localizada na cidade de Tete e Província de Tete.

Os estudos foram levados a cabo, revelam grande contribuição na medida em que as abordagens mais viradas aos membros do conselho escolar em relação as direções das escolas, que não observam a relevância da estrutura do organograma de LigaçãoEscola e Comunidade (LEC). Do estudo feito, os resultados mostraram numa grande medida o papel no ato de consolidação da importância da participação eficiente da comunidade, e é perceptível na escola no ponto comum destas duas lideranças. No caso de Moçambique em concreto, pouca é a literatura sobre a matéria a ser desenvolvida neste artigo, portanto, a reflexão vai motivar maior interesse aos leitores, despertando assim, o maior contributo no campo de análise sobre o tema.

Esta pesquisa está direcionada para os aspectos considerados relevantes na perspectiva dos autores e espera-se que: sirva como ponto de referência para outros trabalhos de investigação; que o MINED dê subsídios evidentes para o fortalecimento do desempenho dos Conselhos Escolares; permitir a relação entre as funções legisladas ao Conselho Escolar e as decisões que o mesmo órgão tem tomado ao longo do seu funcionamento.

\section{CONCLUSÃO}

A pesquisa ação sobre o papel do Conselho Escolar no desempenho das escolas primárias em Moçambique, fundamentada no referencial teórico de Gramsci, permite apresentar algumas conclusões: O Conselho Escolar é espaço público onde os pais, 
a comunidade e os funcionários encontram-se para discutir e tomar decisões de natureza pedagógica e administrativa. Por isso, este órgão é considerado um meio de exercer o seu papel nas instituições que confere, desde que ele seja tratado como uma ferramenta democrática. Contudo, para melhor enquadramento das conclusões da pesquisa, é importante recordar o contexto do surgimento dos órgãos de Conselhos Escolares em Moçambique e da pergunta que orientou o desenvolvimento desta pesquisa. De maneira que foi referido, o Conselho Escolar foi criado com estado moçambicano tendo o objetivo de envolver os pais na busca de soluções dos problemas originados em parte pela massificação do ensino. De salientar ainda que a pesquisa tinha por objetivo responder algumas questões: Conhecer na essência a razão do fraco desempenho deste órgão? Qual envolvimento correto no papel que poderia colocar este órgão na participação efetiva. Como órgão que esta em sintonia na administração das escolas. Será que os membros que formam o conselho escolar têm reunido requisitos adequados e correspondentes às funções para ajudar a sua escola, de modo a ter a precisão de implementar o plano (MINED, 2008).

Embora as escolas tenham criado os Conselhos Escolares, em forma de cumprimento da diretiva do manual em vigência, o seu funcionamento constitui um desafio para todos os intervenientes do processo de ensino aprendizagem. Assim, no estudo identificou-se alguns constrangimentos que, provavelmente, estejam a impedir ao Conselho Escolar de se desenvolver como espaço democrático de decisões participativas, com destaque para a falta de: capacidade de persuasão nos momentos da participação dos processos decisórios; tempo de encontros regulares dos membros do Conselho Escolar; motivação dos membros do Conselho Escolar, etc.

Tenho a referir que o fortalecimento do papel do Conselho Escolar, deve estar vinculado ao compromisso sócio-político da comunidade, sendo essa construção resultado da participação permanente, tomando em vista as seguintes práticas: eliminar as práticas de gestão centralizadas; acautelar o nível de capacidade de debate nos segmentos e consolidar a participação efetiva na tomada de decisões.

O estudo revelou igualmente que a escola funciona segundo uma estrutura vertical, com o diretor no topo e os outros nos escalões inferiores, aliás, esta é a estrutura 
formal em vigor nas escolas públicas, conforme plasmado na Política Nacional de Educação (PNE).

No que concerne a contribuição do Conselho Escolar, a legislação, associa o funcionamento pleno do órgão, a melhoria do desempenho dos alunos, na medida em que os pais podem acompanhar regularmente o desempenho dos seus filhos (MEC, 2005). No caso da EPCC apesar de trabalhar em ambientes urbano o Conselho de tutela possui aspectos como dos vários outros que podem revelar alguns aspectos para o seu fracasso, tais como: ausência do presidente do Conselho Escolar, como consequência, fica em causa a consolidação do papel do mesmo; menos envolvimento dos pais no Conselho Escolar; exigência de remuneração para os membros do Conselho Escolar por parte do Conselho e falta de ações de capacitação para os membros do Conselho Escolar o que pode contribuir para o seu enfraquecimento (MEDEIROS e OLIVEIRA, 2008).

\section{REFERÊNCIAS BIBLIOGRÁFICAS}

CURY, C.R.J. (2004). Os conselhos de Educação e a Gestão o Sistema. In Ferreira, N.S.C \& Aguiar, M.A.S (orgs). Gestão de Educação. Impasses, Perspectiva e Compromisso.

GRANDE DICIONÁRIO ENCICLOPÉDICO VERBO (1997). II Volume, Editorial Verbo. Lisboa/São.

GUEDES, E.C. (2009). Educação o que é. Disponível a 10 de Maio de 2011 em http://www.slideshare.net/edsonguedes/educacao-o-que?

FERREIRA, A.B.H. (2009). Novo dicionário Aurélio de Língua Portuguesa. 4르 Edição. Editora Positiva.

FERREIRA, N. S \& AGUIAR, M. A. (2004). Gestão da educação: impasses, perspectivas e compromissos (Orgs). ( $4^{a}$ ed.). São Paulo: Cortez. 
FONSECA, A.J.D. (1998). A Tomada de Decisões na Escola: A área da Escola em acção, Texto Editora, Lisboa.

LUCK, H. (2006). Gestão educacional: uma questão paradigmática. v. 1. Petrópolis: Vozes.

LUIZ, M.C \& Conti, C (s/d). O papel dos Conselhos de Escola no Sistema Municipal de Ensino.

MEDEIROS, A \& Oliveira, F.F (2008). Conselho Escolar: mecanismo de democratização ou burocratização? Volume 12, n¹, Janeiro • Abril 2008. Disponível a 15 de Maio de 2012 em http://www.unisinos.br/publicacoescientificas/images/stories.

MARCONI, M. A \& Lakatos, E. M (2002). Técnicas de Pesquisa: Panejamento e execução de pesquisas, amostragens e técnicas de pesquisas, elaboração, analise e interpretação de dados. São Paulo: Atlas.

MINISTÉRIO DA EDUCAÇÃO (2003). Diploma Ministerial ํㅜ 54/2003, de 28 de Maio. Maputo.

MINISTÉRIO DA EDUCAÇÃO (2005). Resolução no 8/2005- Aprova os qualificadores dos directores e chefes de Secretarias das Escolas. Maputo.

MINISTÉRIO DA EDUCAÇÃO (2008). Diploma Ministerial ํo 46/2008, de 14 de Maio. Maputo.

MINISTÉRIO DA EDUCAÇÃO E CULTURA (2005). Manual de Apoio ao Conselho de Escola. Moçambique.

MINISTÉRIO DA EDUCAÇÃO E CULTURA (2008). Regulamento Geral do Ensino Básico. Moçambique.

OLIVEIRA, D.B (2000). Conceito e Educação. Disponível a 9 de Dezembro de 2011 em http://www.ebah.com.br/content/ ABAAAATI8AJ/conceito-educação. 
REBOUL, O. (1971). O que é Educar. Disponível a 13 de Setembro de 2011 em http://www.leonildo.com.educa.htm.

Enviado: Julho, 2020.

Aprovado: Outubro, 2020. 